\title{
PROFESSIONAL DEVELOPMENT AND HUMAN RESOURCES MANAGEMENT IN NETWORKS
}

\author{
Evgeniy Rudnev \\ Moscow State City Pedagogical University, Russian Federation \\ E-mail: leadershiprudnev@yahoo.com
}

Submission: 10/10/2015 Accept: 05/02/2016

\section{ABSTRACT}

Social networks occupy more places in development of people and organizations. Confidence in institutions and social networking are different and based on referentiality in Internet. For communication in network persons choose a different strategies and behavior in Linkedln, resources of whom may be in different degree are interesting in Human Resources Management for organizations. Members of different social groups and cultures demonstrate some differences in interaction with Russian identity native. There are gender differences behavior in networks. Participating in groups need ethical behavior and norms in social networking for professional development and communication in future.

Keywords: social networks; virtual communication; referentiality; trust; behavior strate-gies; gender differences; ethics in social networking 


\section{INTRODUCTION}

In paper «Worker autonomy and the drama of digital networks in organizations» (1999) Philip Brey wrote, that people including into digital networks is «technological drama". However, a few years later there are studies that reveal different aspects of behavior and building networks: on network power and globalization (GREWAL, 2003), networks (SCHULTZ-JONES, 2008), sub-networks, uncertainty and knowledge sharing (MILAR; CHOI, 2010), Source for Information (KJOS, 2009), vertex processes (ALMQUIST. 2013), motif-based characterizations (CUNNINGHAM, et al. 2015), friendship networks and social status (BALL; NEWMAN, 2013), repeated interaction networks (WANG; et al. 2013), modeling of networks (HOFF, et al. 2013), detection of structural features (SCHAUB, et al. 2015), multi-modal dark networks (GERDES, 2014), graphical models for dynamic networks (WIT; ABBRUZZO, 2015) mid size cliques in networks (SLATER; ITZCHACK; LOUZOUN, 2014), the variety of local and global patterns in empirical networks (RICHARDS; WORMALD, 2014), vulnerability and power on networks (BOZZO; FRANCESCHET; RINALDI, 2015), algebraic structures of complex networks (SIMAS; ROCHA, 2015).

Anderson (2008) noted - when other network members are not important to a person, or are disliked, people may actually prefer to disagree with that social network member (and therefore, may be quite comfortable with attitude heterogeneity with the network. In parallel, research is being conducted with the use of network analysis in organizations. For example, on diversity of relationships, and whether an actor's topological position in a social network (GRECH, 2009)

Social networks allow organizations not only to declare themselves, but also be a resource for development of individuals and organizations. The advantage of social networks as opposed to really - existing organizations is on freedom of persons into association or group, which serves as a powerful tool for development: can detect an similar problems; meet with various experiences and options to address them; meet with leading experts in various fields of science and business; share their experiences and to express respect to the opinions and experiences of others. 
DOI: 10.14807/ijmp.v7i2.384

There is not accurate statistics of registered users with the global-social networks. The number of users of Facebook and Twitter ranges of the population of China and India (Fasebook - over 1.25 billion users and more than 240 billion contacts. Contacts, Twitter - 232 million users (PISKORSKI, 2014), and Linkedin close to the population of the United States of America (380 million).

The world's largest professional network is Linkedin (USA). It is the most interesting to study the behavior of adults in the Linkedin network. According to Francesca Gino, Harvard University professor, we have not fully complete information about a person and his purposes in networks. At the same time professional communication networks is useful to the extent that the person is willing to share information with other people. This situation can be compared to the work of on-line platform Cursera.

In this case, the author reveals some exclusive information, which previously shared with the door closed in the audience. However, the mere provision of information is just an excuse for information exchange and communication, but communication between adults.

Block and Grund (2014) answered: "What are the substantive implications that follow for the formation and dissolution of social relationships when individuals have more than one attribute in common? While similarity on more than one attribute might increase opportunities to meet, this does not have to translate into friendship relationships being formed.

Not all of individuals' attributes might be salient and matter when social relationships are formed". Adults, unlike children and teenagers have a rich social experience - both personal and professional. In this connection there may be between people of knowledge differences - a subjective picture of the world that can be both the foundation for the emergence of virtual communication and confidence, and obstacle.

The essence of social networking is the information exchange and social capital building (KOZYREV, 2011), that is personal and professional development by the network resources. "As People already spend a great deal of time engaged in work or education-based activities. Most activities, however, restrict interactions to a 
DOI: 10.14807/ijmp.v7i2.384

limited set of people, implying that people will often be unable to establish new relationships that fit them.

As a consequence, this method of establishing new relationships will entail substantial bredth interaction costs. Broker-based means of establishing new relationships afford greater breadth than is possible through activities" (PISKORSKI, 2014) Information exchange is the process of transferring, presenting and evaluating the visual and contextual information in the network.

Participation in the exchange of information is determined by the motivation of the participant network - passive perception, curiosity, motive to achieve, the search of answer to question, solution and opportunities. A higher degree of development contributes to active participating position of a person in the network.

However, modern social networks for adults are a new type of high-yield companies, based on the exchange of information, advertising sales, restriction to information access for potential employees of the organizations and customers. According Anik (2011) connecting others leads to increased well-being and micro level (matchmaking) can translate into social capital at the macro level (increasing social network density).

The specificity of human presence in the professional network is that a participant is a member of organization - with values and standards of work, and from the other hand is a potential partner in the business and employees of other organizations.

Implementation of human motivation and support of commercial success with social-networking provides a virtual connection. Virtual communication is the degree of contact between people by means of communication network that enables people to carry out information exchange and professional development.

Virtual communication can be described by two characteristics - strength and depth. Strength is the degree of influence is exerted on the person as a result of the information exchange. The strength of the virtual connection is manifested in power provided by one person to another.

However, in a virtual environment, power is manifested differently. For example, to access to some of network members - the person is influencing have to 
DOI: 10.14807/ijmp.v7i2.384

use a few words or expressions of the titles of articles, comments and personal judgments, that to demonstrate a power. Thus, the power of virtual communication is more humane than in real organizations, and the person receiving the information retains freedom of choice in decision.

Depth is the degree of sympathy in virtual environment communication. The depth of the virtual connection is shown in the number of positive assessments of judgments, expert opinions, information which a person shares in social networks, assessment of competencies in the profile.

\section{METHODS AND PROCEDURES OF THE STUDY}

In this study, the case method is used (MAYLOR; BLACKMON,2005) analysis of one case. On the first stage was formed the profile of Linkedin with a total amount of 785 co-contacts. The number of contacts included - professors from the universities of the world with different status and country of origin, General Directors, HR- specialists, journalists, artists, professionals and middle managers - men and women in the ages of 25 to 85 years. Then the file was destroyed as a result of a hacker attack and again restored. Step experiment was 3 months - from cookingyang of March 2015. The study recorded the following:

a) The degree of deviation of repeated contact invitations to participants, were part of a network contacts;

b) Initiatives invitation to contact - before the destruction of the profile, and after.

For the purity of the experiment for a period of recovery profile author of the study initiated contact invitation only parties that were parts of the network.

During the research the following question arises: is different the accepted understanding of confidence in the organizations of traditional type from confidence in social networks? and on what it is based? what and how different people's behavior in a professional network? what are the relations of individual and group? What behavior is coming to more confidence and recognition of the network of professional contacts?

In the study, there were several hypotheses:

a) gender differences in the behavior of online and offline - are no different; 
DOI: 10.14807/ijmp.v7i2.384

b) the national identity plays a role in establishing international contacts;

c) the relationships of individual and group network are determined on the rules established by leader;

d) foreigners are employed in Russia - less trusted than the individuals of Russian identity.

\subsection{Confidence in social networks}

Of particular note is the phenomenon of confidence in social networks. In the human sciences trust is understood as:

- social capital accumulated by society in effective communication (ANTONENKO, 2006, 384);

- the main factor for establishing a long-term communication and integration (KOZYREV 2011, 20);

- community members arising the expectation that the other members are behaving more or less predictably, fairly and with attention to the needs of others, in accordance with certain general rules (FUKUYAMA, 2008, 52).

It is emphasized that without confidence and mutual respect can neither unite people, not to involve various social groups in the process of close and constructive cooperation (KOZYREV, 2011), and society, where there is the trust is able to organize the work of people in a more flexible manner and on a collectivist basis, it is able to delegate more responsibility from the grassroots level.

(FUKUYAMA, 2008) The nature of confidence in social networks differs from the confidence in the institutions of the "traditional" type, which is associated with the motives of the presence in the social network: the search for people on the basis of professional interest; mediation parties who come into contact; ability to communicate at a distance (economic barrier); uncertainty and risk; referentiality as a factor of confidence in social networks.

Watts and Koput (2014) emphasized that diversity can create a structure characterized by suppleness. This occurs because a preference for diversity promotes overlapping and redundant weak ties during the early stages of network formation. 
DOI: 10.14807/ijmp.v7i2.384

Preferentiality is the degree of coincidence of members interests in the network. Than more is a level of referentiality than higher the degree of confidence. However, people having the same interest may be in competition situations. That's why the profiles of network participants often are viewed by their direct competitors.

At the same time, along with the referentiality to establish a virtual communication and confidence can have the same meaning as in normal conversation - attraction (the emergence of man by man perception appeal and sympathy of one of them to another, often not realized) (BODALEV, 2015).

Since the attraction eliminates the unequal relations - on the Internet, it is stronger. We have determined that when agents choose the timing of their decisions strategically, they order themselves in a manner such that those with the best information decide first, and those with worse information are willing to wait in order to learn from early decision makers (ROGERS, 2006)

\subsection{Behavior strategies in Linkedln}

In the social network Linkedin are observed the different behavior strategies participants. The network structure around an object can tell us a lot about that object. (CUNNINGHAM, et al. 2015) Rogers (2006) recognizes, first, each individual has an intrinsic value.

Second, each individual allocates a resource budget across links to others. Third, the benefit that one individual receives from another is the product of the total value of the other agent and the strength of the relevant link. Thus, more valuable agents and stronger links confer greater benefit.

Fourth, the total value of each agent is the sum of the intrinsic value and the benefits from all of the connections to other agents. Thus, value is achieved both through intrinsic value and through high quality connections to other high value agents.

First strategy - leader of the network - the carrier of an idea, often has a scientific degree, a professor or advisor status (more 1000 contacts). Places own materials, presents the materials of others, initiates group discussions, encourages others. As a rule, he (she) has own website, is published offline actively. 
DOI: 10.14807/ijmp.v7i2.384

Maybe to monitor other experts and comment their expert materials or opinion. Responds to letters, socially active, has a wide range of contacts - from the thousands and above, has a global impact - strong and deep the virtual connection.

The main motives - self-assertion, expanding influence, support status. The high level of personal point of view, personality. Not more than $5 \%$ of the total number of participants in the network. From the point of view of personaldevelopment and personnel management in the organization can be useful as an expert. However, such people usually have a high degree of selfrealisation, can occupy a managerial position.

Thus, reluctant to sacrifice a freedom, adhering to the organization as an employee. The persons of this strategy have the motives of a higher order, so they can be considered as the invited experts, emphasizing the status-diffract ion with special conditions of employment - a creative work, the work in the project, the quality of the supervisor, more flexible working hours.

Second strategy - expert (500 and more contacts). From 10 to $15 \%$ of the network members. The man, who is a professional in some niche or sector. Unlike the first strategy, people carrier, as a rule, does not produce its own product (texts), but shows a high level of activity in the network (presents, relates to wrote a comment).

One of behavior tactics - information monitoring on the profile and the active exchange of it, which causes a high level of trust and provides a high level of traffic in the network profile. For example, economic pharmacist presents the materials on relevant medicine topics, the specialist on retail on various aspects of retailing - from rent to the current state of retail in Russia, director of environmental projects - with a humorous approach to smoking, furniture design, original, unfamiliar objects of nature that inducing curiosity.

Representatives of this group may exhibit a deviant behavior. In this case, the content is not the same professional context (for example, a sports podiatrist with a French identity - of France, love, gender, art). People who choose this strategy may have a greater need for self-promotion, recognition, raising the status of network resources. Such a person has a wide range of contacts, including abroad. 
DOI: 10.14807/ijmp.v7i2.384

His (her) life may be useful from the point of view of the organization. However, as a rule, such people have sufficient income and status, and the conditions of their employment to wear a personalized character, for example, a higher position in the administrative hierarchy, leadership in meaningful projects providing additional conditions for the application of knowledge and experience. However, such people at least can trust an unknown brands and companies.

Third strategy - specialist - most members of the network. He (she) strives to keep up with the time or go to the networks to address personally significant problems on the advice of friends. May have the status of a premium member. Since this is a fairly broad group, the representatives of this strategy may vary based on job search, coping with risk behavior (selected psychologists, often with some recognition outside the network), representation of the organization in a virtual environment.

Loyal to the network rules - prefer not to take risks, accept invitations from known persons, nothing comment or comment occasionally, showing the position of compromise ("Yes, in part - the truth"), advertise the service corresponding to the profile of their activities or positions of the line sometimes, demonstrate own achievements, which creat the illusion of activity. They have a small circle of contacts in the network from 30 to 500, can use the network of other participants, but are not willing to share his (her). They have a potential interest as employers because some of this group are not satisfied in work now.

Fourth strategy - the refusal to communicate on the network base in Internet. Up to $3 \%$ of the network, as the famous people such as "ordinary" members of the network. Number of contacts - 1-2. The main theme - the reluctance to compress virtually, avoiding unnecessary risks, skeptical attitude to virtual communication, social networks in general.

Give preference to live communication. In some cases, one can observe two files at the party - with the fourth strategy and the strategy of higher order when the person taking the fourth strategy is becoming more active in social networks. With regard to people with a fourth strategy can be applied two kinds of tactics in terms of the potential for real organizations - both offer special work (like the people are 
DOI: 10.14807/ijmp.v7i2.384

choosing the first and the second strategies) as well as a place for the development of abilities, the disclosure of the potential (like working with the third strategy people).

\subsection{International communication in the network}

An indication of orientation to international communication is the profile of the Russian party in English language. Member representing information about himself in his profile in English language, as a rule, has international contacts, and thus can be a source of new contacts abroad and is aimed at a wider circle of colleagues. The experience of building the profile in Linkedin shows that with the support of Russian identity is actively enter into communication carriers other identities (Hindus, Americans, Italians, French, Swedes, British, Australians, Arabs, Austrians, Swiss).

Network analysis provides an intuitive association of social power with access, but it also adds an important qualification: access may impose constraints on autonomy as well as offer opportunities for influence. Network structures and ties also create behavioral expectations: states in certain positions can be expected to play certain roles. For example, (Hafner-Burton, Kahler and Montgomery, 2009) Germany's foreign policy orientation cannot be easily predicted by its overall capabilities, whether military or economic. Its combination of reciprocal constraint within dense, overlapping networks is one that the German elite has maintained since 1945.

That is why the representatives of the nations that show the opposite behavior (by the number of rejections and received invitations) are Germans. Most active in contacts linking are eastern men and representatives of the African continent with a doctoral degree (for example, Iranians, Moroccans, Indians), which may be due the need for greater recognition of the scientists of non-European origin and their contribution to science and the whole interest to Russia as a source of information.

The largest number of rejected invitations shown Norse and Japanese men. In general, immigrants, foreigners (regardless of sex) often initiate contact with his hand, that perhaps due to the more pronounced in this social group needs for social recognition. In general, representatives of oriental culture, demonstrate a greater commitment in the loyalty to the network, which may be due to the collectivist type of most Eastern cultures. As Merluzzi, Hitler (2010) write "vary in their emphasis towards cooperation versus individual achievement". 
DOI: 10.14807/ijmp.v7i2.384

Most social groups in the Linkedln network belongs to the Americans, which are associated in general with a focus on the theme of leadership (assuming the initiative in the debate) and socionic approach to research, is quite common in the United States, as a social norm in science.

Monitoring shows that in general, Americans exhibit the behavior inherent in and outside the Internet, in particular, the priority of the protection of private property and the rights to it. In social groups, there is a tolerant attitude towards a foreigners. At the same time to place comments in the first stage in a group, they are reviewed and censored leader or moderator, and then placed for access to other members of the group.

Only with the acquisition of confidence - compliance with the adopted rules socialization in the group open access initiatives for commenting or discussion. In general, Americans exhibit a twofold relation to the comments of a foreigner - ignored (you will not notice, or rather, simply, to express their own point of view, because in American culture preference is given to the personal - personal - achievements), or react approvingly, show a participation, positive emotions in the comments recognize ("you develop interesting ideas", "this is a decisive factor-conductive," etc.)

Currently, Americans strive to make a participation in social networks, the social norm. In particular, to consider the information in employment - the presence in the networks to the activity and visits to various resources. Currently, there are legal acts that prohibit doing it. For example, the California agreement privacy. Since such a rule is in the process of social experiment, one can argue about it as controversial.

However, most likely its establishment - a matter of time, because now is formed another social norm, according to which people who are not included in social networks, can be attributed to a group of social phobia. In this connection, such a person may be limited access to certain types of employment or work in employment.

\subsection{Women in Linkedln social network}

Women are actively involved in network of professional contacts. Observations show that women of eastern origin are more active in contacts initiating, independently from affiliation and place of residence (for example, Japanese, Thais or US immigrants with Turkish or Russian roots of Eastern origin). While women of American and European origin are great restraint - curiosity, prefer to contact at the 
DOI: 10.14807/ijmp.v7i2.384

initiative of foreign men (social norms accepted in society (non-Internet) are satisfied in Internet too).

However, this provision is shown is not uniform. The degree of activity of women in contact initiating in social network with a man are depended the position which they occupied in the organization and the degree of entrepreneurship is needed for performing their professional duties (eg, a specialist of the international department of University, HR-consultant, lawyer).

Than more a woman is self-employed or her occupation manifestations enterprise requires, to a greater extent, it "breaks" social norm "initiative in communication comes from man." In addition, we are faced with the opposite behavior, than higher the status of women in the organizational hierarchy, the probability of its rejection of the invitation to dialogue, initiated by the man above.

In general, in case of interruption of contact women tend more often 1.5 to reject the re-invitation to the information exchange as compared to men. Among men, often by re-sloping invitation in the case of interruption of the contact by the representative of creative professions (journalists, artists), it is possible to con-with reference to show.

In other words, in the case of various professions interests of people tend to trust others from the general principles of trust, rather the motive of curiosity or subjective motives. Men and women's network structures differ in several important ways. Although no major differences were found in instrumental networks, males break status boundaries in friendships more often and have higher prestige in the friendship networks. (HASAN, 2010)

Can say that men are more "frivolous" than a woman, that is, make decisions faster - accept or reject, at the invitation. In general, the restoration of confidence that women need more information about the reasons for interruption of the contact. In general, the confidence does not depend on the time of interruption of the contact.

Certain social groups in social networks account for expats (foreigners employed labor in Russia) - in my experience of the European ranks men (French, Italians, Germans). In general, expats demonstrate a high level of confidence that can be associated with one hand, with a higher level of trust in society in Europe. 
DOI: 10.14807/ijmp.v7i2.384

On the other hand, the need for friends with the Russian national identity. The hypothesis that expats have less trust in the interruption of contact than the kind of native national identity has not been confirmed.

\subsection{Social groups and human in the network}

Box-Steffensmeier, Christenson (2014) in their research noted while many of the same factors shape membership networks, religious, labor, and political organizations do not share the same structure as each other or as the business, civic and professional groups.

In social networks, people can belong to a large number of social communities on the basis of professional interests - the content of the groups can be complementary or similar, and the degree of participation - a leading member of influencing, making the first steps. Experience in building my own profile showed that enter social group is more difficult during the initial entry, which can be a link, but the lack of experience at the initial stage of networks use, as well as the fact that this procedure is determined the rules are established by the leader - the initiator of the group.

Carter and Dechurch (2012) emphasize that the leadership in the network describes a set of people and models of influence-relations binding them. The direction and understanding of patterns provides an understanding of the impact of the adoption of rules in the group. In general, at the present stage, many previously closed groups tend to be more open, due to the limited resources to the development of the group, in this case, and greater opportunities for the development of specialists, including heads of organizations.

G.B. Schmidt showed that the development of the group depends on how leaders can best facilitate communication and to ensure coordination between people, as opposed to face to face communication in real organizations. (SCHMIDT, 2014)

The more participants in the group, the more opinions and richer information exchange, the smaller - the exclusive opinion or information, but less influenced by the group on the network. Increasingly popular hypothesis of belonging to a not-how many teams in the network and their interaction with each other as a team can surface treat the problem, and in the interaction, dance with others - to offer new 
DOI: 10.14807/ijmp.v7i2.384

solutions that ultimately poses-wills to make innovation more feasible. (Sullivan, Lungeanu, Dechurch, 2015)

\subsection{Ethical aspects of network communication}

Despite the rules established directly with the developers of networks - has not developed standards relating to communication on the Internet. The problem of ethics is becoming one of the leading modern research. (NEUBERT; WU; ROBERTS, 2013). However, the standards that enhance the exchange of information for the personal development of professionals in the organization and human resources management in general are necessary:

- Borrowing contacts moderation. Excessive borrowing contacts as a result of the establishment of a virtual connection can lead to the interpretation of the individual consumer type and reduce the level of trust. In addition, it can narrow circle of contacts and cause a negative opinion about human behavior in the network.

- Positive attitude to people. The criticism, disagreement, difference in points of view are appropriate in a social network, and can extend the view of the considered professional problems. Overall, however, more positive views in attitude - assessment - create a greater confidence and promote a mutual recognition in the social network.

- Express their point of view. Attitude to others' opinions and positions indicates a greater openness, reveals the motivation rights, increases the attractiveness for other people, the number of invitations based on the reference and the number of contacts, and hence the power of the virtual link.

- Information about professional events or work. Sharing personal professional information - where and what is happening, what a busy man expands an idea of a person as a professional, aspects of his life in the profession. A different experience and approach to work form the idea of individuality.

In social networks, you can watch some incidents. In particular, the person with 3000 contacts can bind 15 million. Professionals, and a man with 300 contacts 17 million, due to the choice of strategy in building a network. The wider interest of a 
DOI: 10.14807/ijmp.v7i2.384

person and the more curiosity as a personal quality, the broader outlook and chat more opportunities for the development of richer information exchange, professional development activities, information for organizations development.

Thus, social networks provide opportunities for professional development and human resources management in organizations.

\section{References:}

ALMQUIST, Z. W. (2013) Vertex Processes in Social Networks. A dissertation Doctor of Philosophy in Sociology. University of California, Irvine.

AN, W.; MCCONNELL, W. R. (2015). The origins of asymmetric ties in friendship networks: From status differential to self-perceived centrality. Network Science. n. 3, p. 269-292

ANDERSON, B. D. (2008) How Social Networks Influence Attitudes: Social and Informational Effects of Attitude Heterogeneity and Arguments. A dissertation Doctor of Philosophy. University of Minnesota.

ANIK, L. (2011). Experiments in Social Networks. A dissertation Doctor of Philosophy. Harvard Business School. Cambridge.

ANTONENKO, I. V. (2006) Socio-psychological concept of trust. Monography. FlintMoscow: Science. p. 480.

BABB, D. L. (2004) Factors Influencing Use of Virtual Private Networks Over Traditional Wide Area by Decision-Making Technology Managers. A dissertation Doctor of Philosophy. Capella University.

BAGROW, J. P.; LENMANN, S.; AHN Y. -Y. (2015) Robustness and modular structure in networks. Network Science, September, p.1-17.

BALL, B.; NEWMAN, M. E. J. (2013) Friendship networks and social status. Network Science, n. 1, p. 16-30

BLOCK, P.; GRUND, T. (2014). Multidimensional homophily in friendship networks. Network Science, n. 2, p. 189-212 (про подростков)

BOX-STEFFENSMEIER, J. M.; CHRISTENSON, D. P. (2015). Comparing membership interest group networks across space and time, size, issue and industry. Network Science, n. 3, p. 78-97

BOZZO, E.; FRANCESCHET, M.; RINALDI, F. (2015). Vulnerability and power on networks. Network Science, 3, pp 196-226

CARTER, D. R.; DECHURCH, L. A. (2012). Networks: The Way Forward for Collectivistic Leadership Research. Industrial and Organizational Psychology, n. 5, p. 412-415

CUNNINGHAM, P.; HARRIGAN, M.; WU, G.; O'CALLAGHAN, D. (2013)

Characterizing ego-networks using motifs. Network Science, Available on CJO p. 121 
FERMERLUZZI, H. J. (2010) Informal Networks and The Modern Professional Managerial Career: Decisions and Outcomes. A dissertation Doctor of Philosophy. University of Chicago, Chicago.

FUKUYAMA, F. (2008) Trust: virtue and the path to prosperity: lane. From English. F. Fukuyama. - Moscow: AST, Moscow. 730p.

GERDES, L. M. (2014). MAPPing dark networks: A data transformation method to study clandestine organizations. Network Science, n. 2, p. 213-253

GRECH, K. E. (2009) Personality attributes of actors in social networks. A dissertation Doctor of Philosophy in Human and Organizational Systems. Fielding Graduate University.

GREWAL, D. S. (2003) Network Power and Globalization Ethics. International Affairs, V. 17 , n. 2, p. 89-98

HAFNER-BURTON, E. M.; KAHLER, M.; MONTGOMERY, A. H. (2009). Network Analysis for International Relations. International Organization, n. 63, p. 559-592

HASAN, S. (2010) Social Networks, Stratification and Careers in Organizations. A dissertation Doctor of Philosophy. Carnegie Mellon University.

HOFF, P.; FOSDICK, B.; VOLFOVSKY, A.; STOVEL, K. (2013). Likelihoods for $\square$ xed rank nomination networks . Network Science, n. 1, p. 253-277

KOZYREV, P. M. (2011) Confidence and its resources in the modern Russian; Institute of Russian Academy of Sciences Institute of Sociology. p. 172.

LEE KJOS, A. (2009) The Role of Social Networks in Medication Information Seeking Behavior. A dissertation Doctor of Philosophy. University of Minnesota.

MAYLOR, H.; BLACKMON, K. (2005) Researching Business and Man-agement. Palgrave Macmillan, NY. - 466p. -241p.

MILLAR, C. C. J. M.; CHOI, C. J. (2010) Networks, Social Norms and Knowledge Sub-Networks. Journal of Business Ethics, n. 90, p. 565-574.

NEUBERT, M. J.; WU, C.; ROBERTS, J. A. (2013). The Influence of Ethical Leadership and Regulatory Focus on Employee Outcomes. Business Ethics Quarterly, n. 23, p. 269-296.

NONINO, F. (2013). The network dimensions of intra-organizational social capital . Journal of Management \& Organization, n. 19, p. 454-477

NOVICHKOVA, N.; SMIRNOV, V. (2014) Organizational community on social networks. Problems of theory and practice of management. 8, pp78-85

PHILIP, B. (1999) Worker autonomy and the drama of digital networks in organizations. Journal of Business Ethics, n. 22, p. 15-26

PISKORSKI, M. J. (2014) A social strategy: How we profit from social media. Prinston Iniversity Press. p. 276.

PSYCHOLOGY OF COMMUNICATION. ENCYCLOPEDIC DICTIONARY (2015)। under the general editorship A. A. Bodalev. 2nd ed., Rev. and add. - Moscow; Publishing House "Cogito Center", 672p.

RICHARDS, W.; WORMALD, N. (2014). The evolution and structure of social networks. Network Science, n. 2, p. 326-340 
DOI: 10.14807/ijmp.v7i2.384

ROGERS, B. W. (2006) Learning and Status in Social Networks, A dissertation Doctor of Philosophy. California Institute of Technology, Pasadena.

SCHAUB, M. T.; LEHMANN, J.; YALIRAKI, S. N.; BARAHONA, M. (2014) Structure of complex networks: Quantifying edge-to-edge relations by failure-induced flowredistribution. Network Science, Available on CJO, p. 1-24

SCHMIDT, G. B. (2014). Virtual Leadership: An Important Leadership Con-text. Industrial and Organizational Psychology, n. 7, p. 182-187

SCHULTZ-JONES, B. (2009). Examining information behavior through social networks. An interdisciplinary review. Journal of Documentation. v. 65, n. 4, p. 592631

SIMAS, T.; ROCHA, L. M. (2015). Distance closures on complex networks. Network Science, 3, pp 227-268

SLATER, N.; ITZCHACK, R.; ORAMLOUZOUN, Y. (2014). Mid size cliques are more common in real world networks than triangles. Network Science, n. 2, p. 387-402

SULLIVAN, S. D.; LUNGEANU, A.; DECHURCH, L. A.; CONTRACTOR, N. S. (2015) Space, time, and the development of shared leadership networks in multiteam systems. Network Science, Available on CJO, p. 1-32

WATTS, J. K. M.; KOPUT, K. W. (2014). Supple networks: Preferential attachment by diversity in nascent social graphs. Network Science, n. 2, p. 303-325

WIT, E.; ABBRUZZIO, A. (2015). Factorial graphical models for dynamic networks. Network Science, n. 3, p. 37-57 